\title{
The Intellectual Structure of Creative Industries Studies in 2003-2012: Invisible Taiwan
}

\author{
Chin-Yu Chen and Jwu-Jenq Chen
}

\begin{abstract}
This study explores creative industries studies by analyzing 20,345 citations of 999 articles published in SCI and SSCI journal in web services area between 2003-2012, These amount database conducts citation and co-citation analysis to identify the most important publications, scholars, and research themes in the creative industries and then maps the intellectual structure of creative industries studies between 2003-2012. In this study the author adopted bibliometric [1], social network and tag clouds analysis techniques to investigate the intellectual pillars of the web services literature. The results of the mapping can help identify the research direction of creative industries and helps profile the invisible network of knowledge production in creative industries and provides important insights on current research paradigms of creative industries studies.
\end{abstract}

Index Terms-Creative industries, intellectual structure, bibliometric, tag clouds, paradigms

\section{INTRODUCTION}

Creative industries referred to as the cultural and creative industries, often means to integrate with the cultural and creative industries in Taiwan. The word "culture" has many different definitions. Broadly speaking refers to people living together in a society that have similar habits, customs, and beliefs. Narrow sense which means the "art" is through the people to create new types of product. Whether narrow or broad cultural and creative that is both cultural join each country, ethnic group, and individual creativity, to given cultural style and value.

According human history the industrial development policies for the cultural and creative face first creative industries driven by England premier Tony Blair, Labour Cabinet in 1997, the same period, the aftermath of the Asian financial crisis in South Korea, under the auspices of the South Korean President Kim Dae-jung also began from film and digital cultural content industry began to develop other industries and the establishment of the culture content Agency and Promotion Act of cultural content. Similar practices, including Australia, New Zealand and European countries.

The Creative Class now comprises nearly forty million Americans, or more than $25 \%$ of all employed people. The choices these people make have already had a huge economic impact, and in the future they will determine how the workplace is organized, what companies will prosper or go bankrupt, and even which cities will thrive or wither [2].

The other hand, the positive approach of Taiwan's creative

Manuscript received May 9, 2013; revised July 13, 2013

The authors are with the College of Management, Chang Jung Christian University, Taiwan, R. O. C (e-mail: philosophysun @yahoo.com.tw). industries, the Executive Yuan in May 2002 in accordance with the "Challenge 2008: National Development Plan" determine the development of cultural and creative industries plan began to actively promote research and development.

2013, the 85th Annual Oscar for Best Director in the fierce competition was by Taiwanese director Ang Lee, "Junior PI fantasy drifting" (Life of Pi). This is Ang Lee won the Oscar for best director for the second time, again defeating Hollywood director Steven Spielberg. This is the common pride to all of Taiwanese, because the film's shooting scene was in Taichung City of Taiwan. Via Ang Lee's film introduce Taiwan to the global. This fact let us can't ignore the marketing power of cultural creative industries to the national image.

\section{STUdies OF ACADEMIC LiterATURE}

Among various quantitative methods developed in the last three decades, citation and co-citation analysis is the earliest and the most commonly accepted method. While researchers from different fields practice citing in various ways and for various reasons, Chandy \& Williams (1994) contended that citations are the explicit linkage between articles with common elements [3].

There are a number of techniques that can be used to study a body of literature. Most frequent is the simple literature review where a highly subjective approach is used to structure the earlier work. Objective and quantitative techniques have recently become popular with more databases available online for use. These techniques adopt author citations [4] to examine the invisible knowledge network in the communication process by means of written and published works of a given field. These techniques are attractive because they are objective and unobtrusive [5]. Several studies have used the bibliometric techniques to study the literature of management research. For example, Etemad [6] identified the most influential authors and studies in electronic commerce field by using citation analysis; Ramos-Rodriguez and Ruiz-Navarro [7] examined the intellectual structure change of strategic management research by conducting a bibliometric study of the Strategic Management Journal. To the best of our knowledge, no similar study has been conducted on the current research of knowledge management. Therefore this study aims to fill a gap in knowledge management literature by applying citation and Tag cloud analysis to a representative sample of recent research on creative industries collected by the Science Citation Index and Social Sciences Citation Index.

In this study also use Tag cloud to reveal the most research key words in creative industries. Tag clouds have proliferated 
over the web in the past decade. One of the most exciting recent developments in web science is social network that enables users to easily annotate web content using free form keywords [8]-[9]. They provide a visualization of a collection of simple texts by visually depicting the tag frequency by font size. In use, tag clouds can evolve into the associated data source over time. Results in this study can be provided valuable references for academic circles and related industries.

\section{Methodology}

The citation data used in this study included journals, articles, authors, nations. Based on the objective of this study, the authors explored the intellectual structure of web services between 2003 and 2012. This time period was chosen because contemporary web services studies of the last ten years represent the most update and probably also the most important research on web services. Citation and co-citation analysis is the main method for this study.

First, the databases were identified as the sources of web services publications. Then data collection and analysis techniques were designed to collect information topic about articles, journals, authors and nations on web services research.

As information and information systems become increasingly valuable and information technology advances at a fast pace, only creative and innovative companies will be able to survive the competition in the new millennium, by utilizing the emerging information technologies and innovative management methods.

In this study the author expect to explore the creative industries in trends of Taiwan. So next paper the author will summarizes the government policies, progress, organization and obstacles in the development of Taiwan's DCI and compares these subjects with other countries, including the United States, EU countries, Japan, and Korea...etc. The author predicts that Taiwan's creative industries opportunities and challenges will be just around the corner.

\section{RESULTS}

Table I presents the top 20 cited NATIONS in creative industries during 2003 2012, in the before and the after 5 years, there were changed obviously of the highest number of citations of the top 20 countries, make comparisons because the first 5 year period, Taiwan's creative industries study is seventeenth; then the recently 5 years period, has been promoted to sixth, it shows Taiwan social science researcher has noticed this area, and the manpower has increased dramatically the past 5 years invested in the cultural and creative industries.

According the WOS download between 2003- 2012 years, scholars have published in SSCI and SCI cited the most number of papers, the author found that five years ago in Taiwan is number 17, after five years, has been promoted to the first seven, the author find the two stages of the top six countries did not change, but the rank of position in the name list reveal that Taiwan is promoting. This display considerable significance for scholars of Taiwan's cultural and creative industries. Looking the Table I, the cultural and creative industries more famous is about the United States, Australia, England, Canada, Germany, Sweden, and the seventh is Taiwan.

TABLE I: TOP 20 CITED NATIONS IN CREATIVE INDUSTRIES IN 2003 2012

\begin{tabular}{|c|c|c|c|}
\hline $\begin{array}{c}\text { Articles } \\
\text { 2003 2007 }\end{array}$ & Frequency & $\begin{array}{l}\text { Articles } \\
\qquad 2008 \sim 2012\end{array}$ & Frequency \\
\hline USA & 93 & USA & 157 \\
\hline ENGLAND & 36 & AUSTRALIA & 90 \\
\hline AUSTRALIA & 23 & ENGLAND & 87 \\
\hline CANADA & 13 & CANADA & 32 \\
\hline GERMANY & 12 & GERMANY & 31 \\
\hline SWEDEN & 8 & SWEDEN & 25 \\
\hline NETHERLANDS & 6 & TAIWAN & 24 \\
\hline FRANCE & 6 & NETHERLANDS & 24 \\
\hline JAPAN & 6 & SPAIN & 19 \\
\hline PEOPLES R CHINA & 5 & ITALY & 16 \\
\hline DENMARK & 5 & NEW ZEALAND & 16 \\
\hline NEW ZEALAND & 5 & SCOTLAND & 15 \\
\hline SWITZERLAND & 5 & PEOPLES R CHINA & 14 \\
\hline ITALY & 5 & SOUTH KOREA & 12 \\
\hline SCOTLAND & 4 & FRANCE & 9 \\
\hline INDIA & 4 & FINLAND & 7 \\
\hline TAIWAN & 3 & NORWAY & 7 \\
\hline SPAIN & 3 & SINGAPORE & 7 \\
\hline WALES & 2 & INDIA & 7 \\
\hline BELGIUM & 2 & LITHUANIA & 6 \\
\hline
\end{tabular}

TABLE II: 999 RECORDS TOPIC $=($ CREATIVE INDUSTRIES $)$

\begin{tabular}{|l|l|l|}
\hline Field: Research Areas & $\begin{array}{l}\text { Record } \\
\text { Count }\end{array}$ & \% of 999 \\
\hline BUSINESS ECONOMICS & 404 & $40.440 \%$ \\
\hline GEOGRAPHY & 134 & $13.413 \%$ \\
\hline $\begin{array}{l}\text { ENVIRONMENTAL SCIENCES } \\
\text { ECOLOGY }\end{array}$ & 100 & $10.010 \%$ \\
\hline ENGINEERING & 95 & $9.510 \%$ \\
\hline PUBLIC ADMINISTRATION & 75 & $7.508 \%$ \\
\hline COMMUNICATION & 73 & $7.307 \%$ \\
\hline URBAN STUDIES & 73 & $7.307 \%$ \\
\hline CULTURAL STUDIES & 57 & $5.706 \%$ \\
\hline SOCIOLOGY & 54 & $5.405 \%$ \\
\hline SOCIAL SCIENCES OTHER TOPICS & 50 & $5.005 \%$ \\
\hline Timespan=2003-01-01 2012-12-31 &
\end{tabular}

Timespan=2003-01-01 2012-12-31

Database=SCI-EXPANDED, SSCI

Via WOS Results Analysis display that the top 10 research areas reveal that the creative industries studies more than $50 \%$ focus on business economics and geography issues, but the culture studies is only $5.706 \%$. Therefore, in the study of 
creative industries research, there is still a large space to effort in the culture field.

The Table II above shows the nature of the concept of cultural and creative industries still on the traditional economic and industrial structure of the production chain: the value of the most intuitive way to assess the cultural art effects still give an economic multiplier of a city, both of the arts and cultural activities terms are sightseeing district or museums. Creative Industries real worth lies in the occurrence of new consumer field. City not only fight for individual consumption only, are also fighting for the working capital of industrial investment, and a variety of service industries, especially high-value, high wisdom intensive industries. But the author ignore the cultural function of cultural and creative industries, that to humanism strategy, culture and the arts can alleviate social problems and improve humanity. More broadly, government cultural construction purposes, that is united multi-ethnic culture, compatible with minority cultures.

TABLE III: TOP 10 CITED JOURNALS IN CREATIVE INDUSTRIES IN 2003 2012

\begin{tabular}{|c|c|c|c|}
\hline $\begin{array}{l}\text { Journals } \\
\qquad 2003 \sim 2007\end{array}$ & Frequency & $\begin{array}{l}\text { Journals } \\
\qquad 2008 \sim 2012\end{array}$ & Frequency \\
\hline $\begin{array}{l}\text { STRATEGIC } \\
\text { MANAGE J }\end{array}$ & 184 & $\begin{array}{l}\text { STRATEGIC } \\
\text { MANAGE J }\end{array}$ & 524 \\
\hline RES POLICY & 174 & RES POLICY & 386 \\
\hline ADMIN SCI QUART & 120 & ACAD MANAGE J & 368 \\
\hline AM ECON REV & 119 & URBAN STUD & 326 \\
\hline ENVIRON PLANN A & 107 & ENVIRON PLANN A & 322 \\
\hline $\begin{array}{l}\text { ACAD MANAGE } \\
\text { REV }\end{array}$ & 100 & ORGAN SCI & 321 \\
\hline ORGAN SCI & 96 & ADMIN SCI QUART & 307 \\
\hline MANAGE SCI & 91 & $\begin{array}{l}\text { ACAD MANAGE } \\
\text { REV }\end{array}$ & 268 \\
\hline REG STUD & 88 & REG STUD & 244 \\
\hline AM J SOCIOL & 86 & J ECON GEOGR & 223 \\
\hline
\end{tabular}

The Table III shows that the creative industries academic journals, the most cited journals and the most academic authority journals, compared of these two stages, the first 5 years of the two periodicals have delete two periodicals of "MANAGE SCI "and "AM J SOCIOL ", and after 5 years replaced "URBAN STUD" and "J ECON GEOGR" These figures on the cultural and creative researchers also have a interesting finding, that the recent five years cited increased nearly three-fold, which shows the latest five years the academic study of creative industries have a significant increase in the quality and quantity progress and transformed.

The author find that from Table4 the most cited authors in the two periods in addition to Scott AJ, Florida Richard, and Grabher G keep are still in the top 5, there appeared another new highly cited authors in the recent 5 years of top 10 authors. We figure out this phenomenon can present the new paradigm has been shifted.
TABLE IV: TOP 10 CITED AUTHORS IN CREATIVE INDUSTRIES IN 2003 2012

\begin{tabular}{|c|c|c|c|}
\hline Authors & Frequency & Authors & Frequency \\
\hline \multicolumn{2}{|c|}{$2003 \sim 2007$} & \multicolumn{2}{|c|}{$2008 \sim 2012$} \\
\hline Scott AJ & 50 & Scott AJ & 161 \\
\hline Grabher G & 44 & Florida Richard & 159 \\
\hline NAGARAJAN K & 39 & Grabher G & 120 \\
\hline Florida Richard & 35 & Pratt AC & 102 \\
\hline Gibson C & 26 & Peck J & 99 \\
\hline GRILICHES Z & 24 & Markusen A & 98 \\
\hline ELIASSON G & 22 & Florida R & 97 \\
\hline TEECE DJ & 22 & Gibson C & 85 \\
\hline COHEN WM & 20 & Florida R. & 85 \\
\hline Nelson R. R. & 20 & Caves R. & 73 \\
\hline
\end{tabular}

TABLE V: TOP 10 CITED ARTICLES IN CREATIVE INDUSTRIES IN 2003 2012

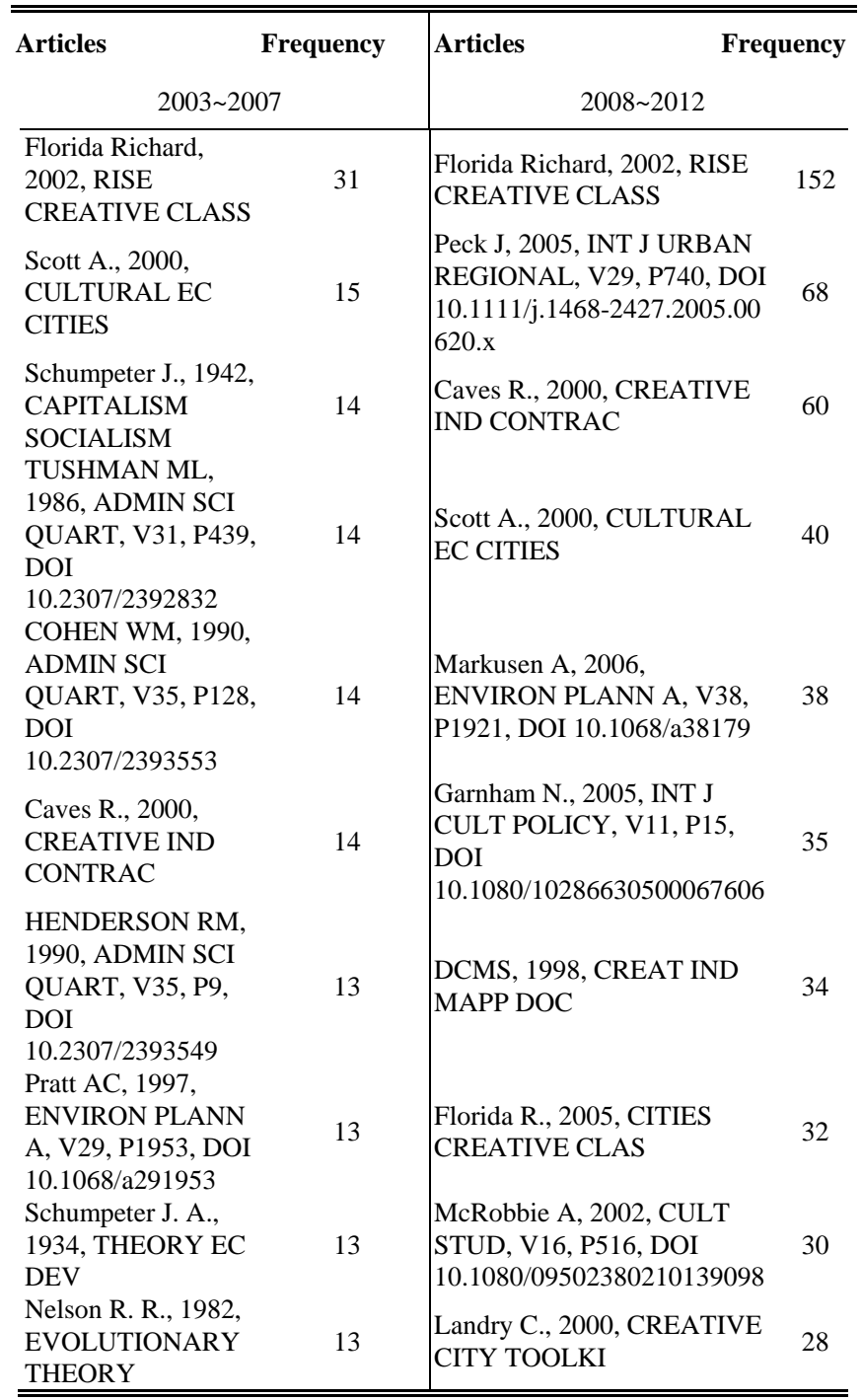

There still a interesting discover that the Table 5 will be from 2003 to 2012, cutting for the first five years and five years after two periods, the contrast between these two stages, the journal published papers in the top ten most cited articles, the first is Florida Richard, 2002, RISE CREATIVE CLASS [10].

This short article summarizes recent advances in our 
thinking about cities and communities, and does so particularly in light of themes advanced in my recently published book, The Rise of the Creative Class [11], which focuses on diversity and creativity as basic drivers of innovation and regional and national growth. This line of work further suggests the need for some conceptual refocusing and broadening to account for the location decisions of people as opposed to those of firms as sources of regional and national economic growth. In doing so, this article hopes to spur wider commentary and debate on the critical functions of cities and regions in 21 st-century creative capitalism.

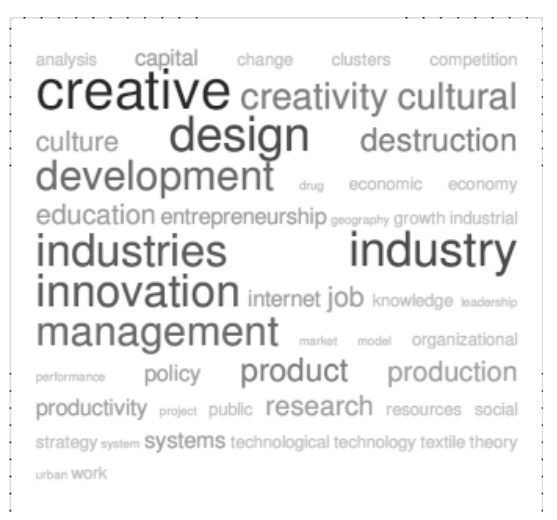

Fig. 1. Tag clouds in key word of web services (2003-2007)

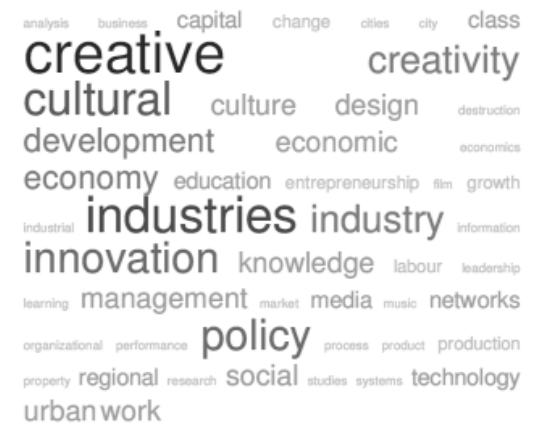

Fig. 2. Tag clouds in key word of web services (2008-2012)

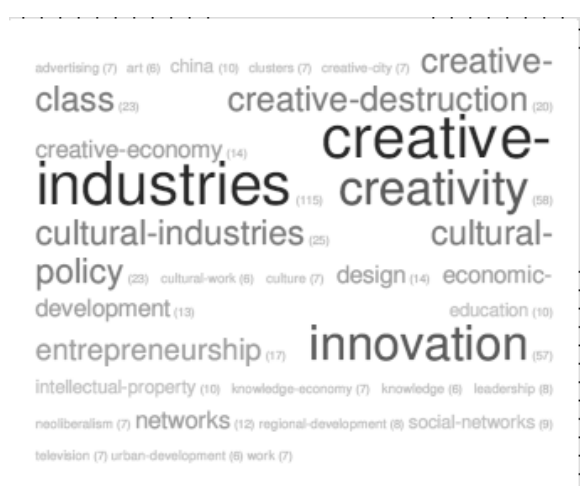

Fig. 3. Tag clouds in key word of web services (2003-2012)

With comparisons of 3 Tag Cloud Figs above, the Fig. 1 displayed in 2003-2007 five years period, the creative industries research keywords were: creative, industries, design, industries, innovation, management. And the Fig. 2 shows that in the 2003-2007 five-year periods, the creative industries research keywords revels that "design" gradually taken seriously and replaced by two words of "policy" and "culture". And the Fig. 3 shows the keywords cited frequencies. This discovery can offer guideline of our research.

The following at the bottom of our scope and authority responsible for Taiwan's cultural and creative industries

1) Following the authority in the Council for Cultural Affairs)

- Visual arts industries

- Music and performing arts industries

- Cultural performances Facilities industries

- Process industries

2) Following the authority in the News Bureau

- film industries

- Broadcast television industries

- Publishing industries

3) Following the authority in the Ministry of Economic Affairs

- Advertising industries

- Design industries

- Designer fashion industries

- Architectural design industries

- Creative life industries

The aim of this article is to critically examine the notion that if the creative industries maybe or maybe not forms research trends in Taiwan.

\section{CONCLUSION}

Matthew7:24-25"Therefore whosoever hearth these sayings of mine, and doeth them, I will liken him unto a wise man, which built his house upon a rock: And the rain descended, and the floods came, and the winds blew, and beat upon that house; and it fell not: for it was founded upon a rock."

The metaphor is perhaps one of man's most fruitful potentialities. Its efficacy verges on magic, and it seems a tool for creation which God forgot inside one of His creatures when He made him [12].

The author cite the paragraph of this chapter of the Bible, is to describe this method of information management, the foundation of academic research, as a new generation of scholars in 21 st century information when working on a new academic field of study, it is necessary to the results of research in this area in the past. Quickly grasp and reference the most powerful discourse, to further explore the topic you want to study from the best journals so only to avoid a repeat of previous studies topics are discussed, and also extends the theory model transfer, so-called standing on the shoulders of giants, the accumulated wisdom of our predecessors, will be let scholars can climb higher!

This study adopted bibliometric, social network and tag clouds analysis techniques to investigate the intellectual pillars of the web services literature. By analyzing 20,345 citations of 999 articles published in SCI and SSCI journal in web services area during 2003-2012, this study conducts citation and Tag cloud analysis to identify the most important journals, articles, authors, and research themes in the creative industries and then maps the intellectual structure of creative industries studies during 2003-2012. The author observed 
the paradigms of creative industries research in 2003-2012 in order to explore Taiwan creative industries.

To approach these issues in a more objective manner, a generic model of invisible network of knowledge (INK) is proposed in this paper that can be used to map the intellectual structure in the creative industries area. With citation and Tag cloud analysis this model is able to explore the intellectual structure of any existent field, delineate its knowledge network, and further portrait its knowledge diffusion process. The invisible network of knowledge is defined in this paper as a set of interlinked invisible nodes represented by the publications with their frequency of citations as well as the correlations of different publications. Each set of such nodes serves a specific purpose for the study of creative industries or any other field of interest. Follow this path and take this method to explore the trend of Taiwan's cultural and creative industries, and this will be the development of research route.

\section{REFERENCES}

[1] D. N. Bellis, "Bibliometrics and citation analysis: from the Science citation index to cybermetrics," Defined: Bibliometrics is a Set of Methods to Quantitatively Analyze Scientific and Technological Literature, Scarecrow Press, pp. 417, 2009.

[2] F. Richard, "The Rise Of The Creative Class: And How It's Transforming Work," Leisure, Community and Everyday Life, 2004.

[3] Z. Ma, D. Liang, and Y. Lee, "Most cited business ethics publications: Mapping the intellectual structure of business ethics studies in 2001-2008," Business Ethics: A European Review, vol. 21, issue. 3, pp. 286-297, June 2012.

[4] A. Pilkington and T. Teichert, "Management of technology: Themes, concepts and relationships," Tec Novation, vol. 26, pp. 288-299, 2006.

[5] E. Garfield, Citation Indexing: Its Theory and Application in Science, Technology, and Humanities, New York: Wiley, 1979.

[6] H. Etemad, "E-commerce: The emergence of a field and its knowledge network," International Journal of Technology Management, vol. 28, pp. 776-800, 2004

[7] A. R. R. Rodriguez and J. R. Navarro, Changes in the Intellectual Structure of Strategic Management Research: A Bibliometric Study of the Strategic Management Journal, Strategic, 1980-2000.
[8] J. Park et al, "A vector space approach to tag cloud similarity ranking," Information Processing Letters, vol. 110, no. 12-13, pp. 489-496, 2010.

[9] B. Lee et al., "Spark Clouds: Visualizing Trends in Tag Clouds," IEEE Transactions on Visualization and Computer Graphics, vol. 16, no. 6, pp. 1182-1189, 2010.

[10] "Rise Creative Class" the key words of Florida Richard published studies.

[11] "The Rise of The Creative Class" is the main title of a series of professional publishing writings of Florida Richard.

[12] Jose Ortega Y Gasset quotes, Spanish philosopher and humanist, 1883-1955.

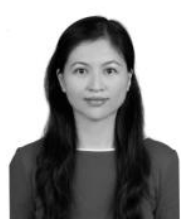

Chin-Yu Chen is a PH.D student comes from Tainan City of Taiwan, R.O.C. She is teaching literature in Nan Jeon Institute of Technology over 15 years. The Institute of Technology located in Yian-shui District of Tainan City. She is also the AOM member and 2013AOM reviewer. Her academic professional original is focus on Taiwan and Chinese, including literature, modern art, linguistics and films. Recently she continues to study business management degree of PH.D in Chang Jung Christian University in Qui-Nhon District of Tainan City. Her academic achievements are mostly in Taiwan, and published in domestic journals. She published a scholarly monograph under the title "Taiwan Literature and Language Studies" in 2008. This paper is the first of her personal papers in the field of management science, also a contributor foreign international conference for the first time, hope to have the opportunity to be accepted, and have the chance to learn more from the knowledge and accumulate academic experience.

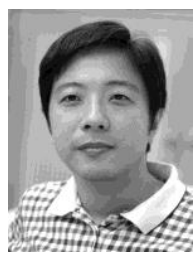

Jwu-Jenq Chen was born in Tainan County in Taiwan. His birthday is August 10th 1972. He received MS degree from the Graduate Institute of computer science, Ohio University in U.S.A., 1996. He is an Associate Professor at the department of Computer Cienceand Information Engineering at the Chang Jung Christian University in Taiwan. He is also a doctoral student at the Graduate School of Business and Operations Management, Chang Jung Christian University. His research interests include management information system and website. 